University of South Florida

DIGITAL COMMONS

Digital Commons @ University of

@ UNIVERSITY OF SOUTH FLORIDA

South Florida

\title{
Winds on the West Florida Shelf: Regional Comparisons between Observations and Model Estimates
}

\author{
Dennis A. Mayer \\ University of South Florida St. Petersburg \\ Robert $\mathrm{H}$. Weisberg \\ University of South Florida, weisberg@marine.usf.edu \\ Lianyuan Zheng \\ University of South Florida \\ Yonggang Liu \\ University of South Florida, yliu@marine.usf.edu
}

Follow this and additional works at: https://digitalcommons.usf.edu/msc_facpub

\section{Scholar Commons Citation \\ Mayer, Dennis A.; Weisberg, Robert H.; Zheng, Lianyuan; and Liu, Yonggang, "Winds on the West Florida Shelf: Regional Comparisons between Observations and Model Estimates" (2017). Marine Science Faculty Publications. 267. \\ https://digitalcommons.usf.edu/msc_facpub/267}

This Article is brought to you for free and open access by the College of Marine Science at Digital Commons @ University of South Florida. It has been accepted for inclusion in Marine Science Faculty Publications by an authorized administrator of Digital Commons @ University of South Florida. For more information, please contact digitalcommons@usf.edu. 


\title{
Journal of Geophysical Research: Oceans
}

\section{RESEARCH ARTICLE Winds on the West Florida Shelf: Regional comparisons \\ 10.1002/2016JC012112 between observations and model estimates}

Key Points:

- Ten years of wind observations are compared with NCEP model

simulations on the West Florida Shelf

- We find that wind stress from NCEP simulations underestimate those derived from observations

- Suggestions are offered to improve the NCEP forcing fields and the consequent modeled circulation

Correspondence to:

D. A. Mayer,

dmayer@mail.usf.edu

Citation:

Mayer, D. A., R. H. Weisberg, L. Zheng, and Y. Liu (2017), Winds on the West Florida Shelf: Regional comparisons between observations and model estimates, J. Geophys. Res. Oceans, 122, 834-846, doi:10.1002/2016JC012112.

Received 30 JUN 2016 Accepted 29 DEC 2016 Accepted article online 5 JAN 2017 Published online 1 FEB 2017

\author{
Dennis A. Mayer1 ${ }^{\mathbb{D}}$, Robert H. Weisberg' ${ }^{\mathbb{D}}$, Lianyuan Zheng1 ${ }^{\mathbb{D}}$, and Yonggang Liu1 \\ ${ }^{1}$ College of Marine Science, University of South Florida, St. Petersburg, Florida, USA
}

\begin{abstract}
Wind fields on the West Florida Continental Shelf are investigated using observations from five University of South Florida Coastal Ocean Monitoring and Prediction System buoys and seven of NOAA's National Ocean Service and National Weather Service, National Data Buoy Center stations or buoys spanning the 10 year period, 2004-2013. These observations are compared with NOAA's National Center for Environmental Prediction (NCEP) reanalysis wind fields (NCEP winds). The analyses consist of vector correlations in both the time and frequency domains. The primary findings are that winds observed on and near the coastline underestimate those observed offshore and that NCEP winds derived from assimilating mostly land-based observations also underestimate winds observed offshore. With regard to wind stress, and depending upon location, wind stress derived from NCEP winds are 6\%-49\% lower than what is computed from observations over open water. A corollary is that wind forcing fields that are underestimated may result in coastal ocean model circulation fields that are also underestimated. These analyses stress the importance of having offshore wind observations, and suggest that adding more offshore wind observations will lead to improved coastal ocean wind fields and hence to improved model renditions of coastal ocean model circulation and related water property fields.
\end{abstract}

\section{Introduction}

Ecologically based management of the coastal ocean requires knowledge of the shelf circulation, a primary determinant in coastal ocean state variable estimation. This in turn requires accurate coastal ocean wind fields along with other forcing functions. Here we consider the West Florida Continental Shelf (WFS), a region known to be forced by a combination of local winds and buoyancy fluxes along with interactions along the shelf slope by the Gulf of Mexico Loop Current (LC) and its eddies [e.g., Weisberg and He, 2003; He and Weisberg, 2003], particularly in the vicinity of the Dry Tortugas in the southwest where the LC may come in contact with shallow water isobaths that must wrap around this westernmost islet of the Florida Keys chain [e.g., Hetland et al., 1999].

Local wind forcing on the WFS exhibits a well-defined seasonal variation [Liu and Weisberg, 2012], which is especially important on the inner shelf that extends out to about the $50 \mathrm{~m}$ isobath [e.g., Li and Weisberg, 1999]. The seasonal variability in the coastal circulation generally modulates the mean southward flow along the shelf Weisberg et al. [2009], where the flow tends to be upwelling favorable from fall to spring months (October-April) and downwelling favorable during summer months (June-September). Because the coastal ocean circulation varies over a broad range of spatial and temporal scales, coastal ocean modeling must incorporate wind fields that are based on the most accurate wind observations. Moreover, accurate wind forcing is also necessary to more accurately diagnose the effects of nonlocal, deep-ocean forcing.

To this end, data from the University of South Florida (USF) Coastal Ocean Monitoring and Prediction System (COMPS), NOAA's National Ocean Service (NOS) and National Weather Service (NWS) National Data Buoy Center (NDBC) were used to examine the spatial and temporal variability of the winds over the WFS. This provided an opportunity to compare observations with NOAA's National Center for Environmental Prediction (NCEP) reanalysis wind fields, henceforth referred to as NCEP winds [Mesinger et al., 2006], that are model simulations used in driving ocean circulation models. The locations of the observations considered herein are provided in Figure 1, where the analysis domain covers an area from $24^{\circ} \mathrm{N}$ to $29^{\circ} \mathrm{N}$ and from $86^{\circ} \mathrm{W}$ to $81^{\circ} \mathrm{W}$. The along shelf scale of the WFS is approximately $550 \mathrm{~km}$ northwestward along the $50 \mathrm{~m}$ isobath. The across shelf scale is approximately 


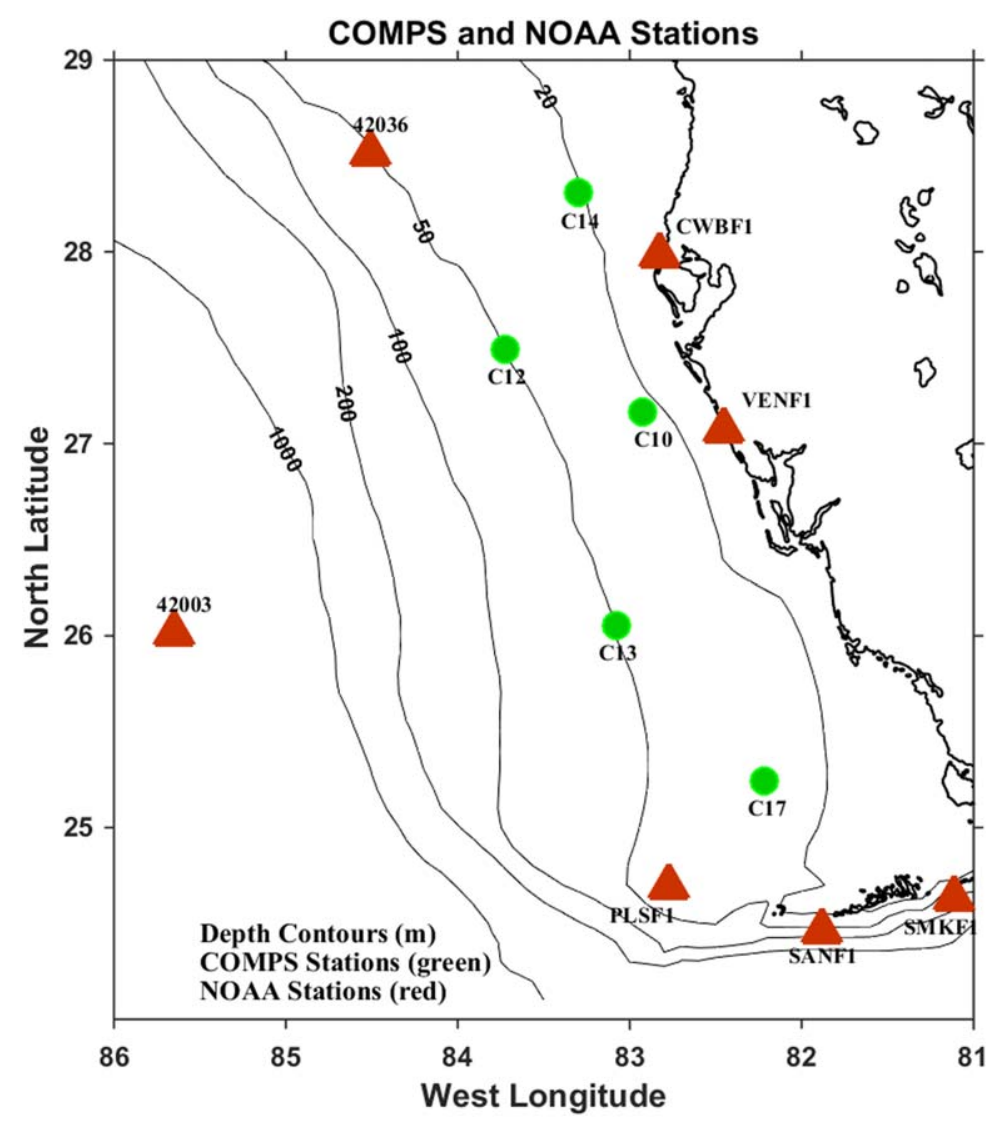

Figure 1. Analysis domain showing NOAA and COMPS stations.
$150 \mathrm{~km}$ from the shoreline to the shelf break. Questions to be addressed are whether or not winds from stations on and near the coastline accurately represent the winds offshore and what if any are the differences between NCEP winds and observations. Further, if NCEP winds are not true to what is observed over open water, can they be improved by exploiting the COMPS observations.

The problems in estimating offshore winds using shore observations are well documented. Weisberg and Pietrafesa [1983] found that shorebased winds underestimate winds over open water in their study in the South Atlantic Bight. Halliwell and Allen [1987] addressed the coastal marine boundary layer off the west coast of North America-a coastline of about 3600 $\mathrm{km}$-where winds offshore showed greater speeds and directions that were different than those along the coast. These findings relate to greater friction over land than over water, plus topographic effects along the coast, and Halliwell and Allen [1987] further tested whether or not a simple formula (proposed by Hsu [1986]) could adjust winds at land stations to those offshore. They concluded that the uncertainty in the regression coefficients and their variability in space and time precluded this approach. Their analysis used two representations of the coastal wind field derived from both shore and offshore observations (separated by about $20 \mathrm{~km}$ ) and geostrophic winds derived from surface atmospheric pressure fields with a boundary layer correction. Both observed and derived winds provided reasonable atmospheric forcing functions, but only for along shelf scales greater than $900 \mathrm{~km}$, a length much larger and with topographic features much different than those of the WFS.

From these regional case studies, it is clear that specifying a wind forcing field in driving coastal ocean circulation models is complex. These issues have been gradually addressed by NCEP, beginning with operational model wind forecasts in 1979 [Mesinger et al., 2006]. These forecasts continue to evolve and improve as more wind observations are utilized in their Data Assimilation System. Wood et al. [2012] shows how difficult it is to find a proxy for wind stress over the coastal ocean when there are few oceanographic observations with application to their regional area off Sydney Australia. The salient point here is the criticality of assimilating observations adequate to provide an accurate wind forecast. An early example of this is documented for the WFS by He et al. [2004] where optimal interpolation was used to blend winds measured in situ with NCEP winds. Their findings from two case studies in the spring of 2001 showed that the ocean circulation model, when forced by the blended winds, performed significantly better than when forced by NCEP winds alone. Without the blended winds, the modeled currents significantly underestimated the amplitude of the observed currents. More recently, Liu and Weisberg [2012] underscored the need for sustained in situ wind observations from buoys and coastal meteorological stations to be assimilated in the NCEP winds because inadequate winds are a major source of error in modeling coastal ocean circulation fields. 


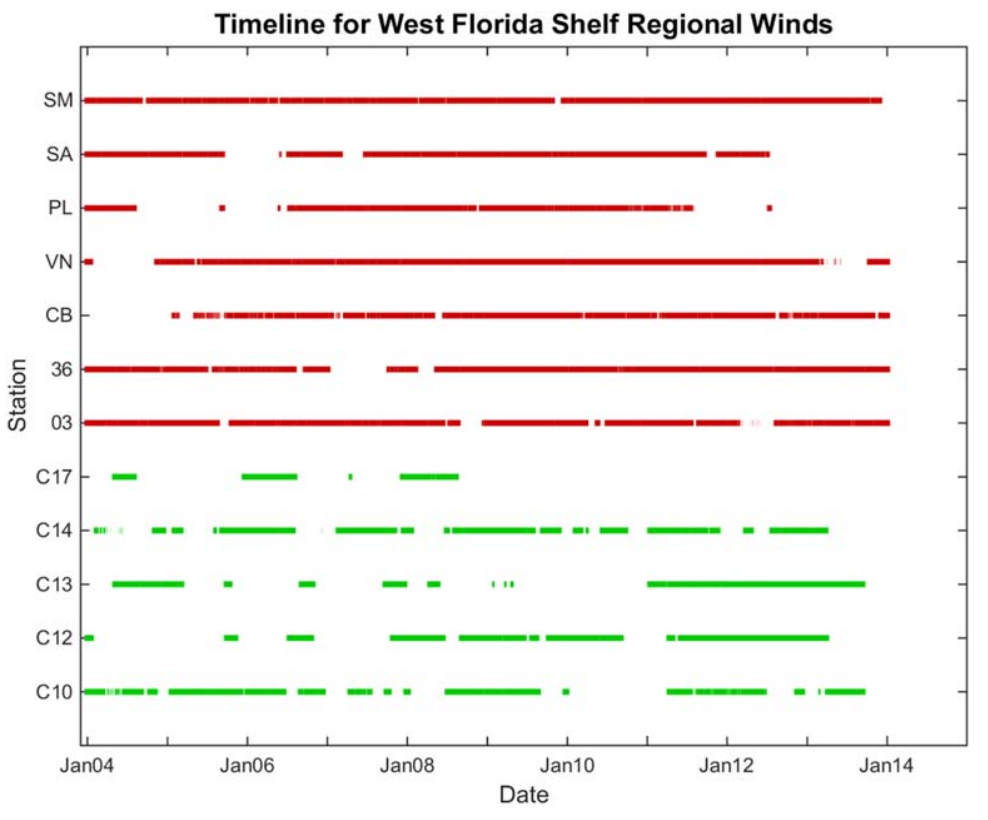

Figure 2. Timeline of available data over a 10 year period from 2004 to 2013 for 12 stations. Among these are seven NOAA stations which are-one NOS station (CWBF1) and six NDBC stations: 42036, 42003, VENF1, PLSF1, SANF1, and SMKF1, and five COMPS stations, the USF surface buoys: $\mathrm{C10}, \mathrm{C} 12 \mathrm{C13}, \mathrm{C14}$, and C17. Labels are SM (SMKF1), SA (SANF1), PL (PLSF1), VN (VENF1), CB (CWBF1), 36 (42036), 03 (42003), and C17, C14, C13, C12, and C10.

\section{Data}

The temporal data coverage, shown in Figure 2, spans the 10 year period from 2004 to 2013. Observations were obtained from 12 stations (Tables 1 and 2). These include seven NOAA stations, the NOS station CWBF1 and the six NDBC stations: 42036, 42003, VENF1, PLSF1, SANF1, and SMKF1 (with data downloaded from http://www.ndbc.noaa. gov) and five COMPS moored buoys: C10, C12 C13, C14, and C17. Provided are the observation heights, locations, start and end times, and record lengths. The timelines in Figure 2 indicate substantial gaps in the COMPS data set that compromise our ability to perform spectral analyses over the full 10 year period. Consequently, spectral analyses are limited to data subsets that are not much longer than a year. Time domain analyses do not have this restriction.

Observations over open water are difficult to maintain because of the hostile environment. The greatest number and longest gaps occur at stations $\mathrm{C} 12, \mathrm{C} 13$, and $\mathrm{C} 17$. It is no coincidence that these stations are the farthest from shore (Figure 1), posing logistical difficulty in maintenance. The gaps are a consequence of a thorough quality control procedure and are due mostly to instrument deterioration and failures. The same quality control procedures were used for the NOAA winds.

All the COMPS and 42036 and 42003 stations are moored buoys over open water. The PLSF1, SANF1, and SMKF1 stations are all towers over open water but are near the coast. CWBF1 and VENF1 are shore stations but are located on piers $100 \mathrm{~m}$ or more away from the shore. Both shore locations provide no significant topographic features that would compromise the wind observations other than the fact that they are on or near land where friction is greater than over water as noted by studies discussed earlier. Details about the NOAA station environment can be obtained from their Web site under "View Station Page." The COMPS stations are described in Weisberg et al. [2009] and Liu and Weisberg [2012]. All of the wind observations from NOAA and COMPS were referenced to $10 \mathrm{~m}$ above sea level fol-
Table 1. USF COMPS Stations, All Open Water Buoys ${ }^{a}$

\begin{tabular}{lcccc} 
Stations & Location & Start & End & Days (Missing) \\
\hline C1O/NA2 & $27^{\circ} 09.70^{\prime} \mathrm{N}$ & 1 Jan 2004 & 10 Sep 2013 & $3540(1265)$ \\
& $82^{\circ} 55.53^{\prime} \mathrm{W}$ & & & \\
$\mathrm{C} 12 / \mathrm{CM} 2$ & $27^{\circ} 29.72^{\prime} \mathrm{N}$ & 1 Jan 2004 & 28 Mar 2013 & $3374(1470)$ \\
& $83^{\circ} 43.47^{\prime}$ & & & \\
$\mathrm{C} 13 / \mathrm{CM} 3$ & $26^{\circ} 03.43^{\prime} \mathrm{N}$ & 7 May 2004 & 9 Sep 2013 & $3412(1789)$ \\
& $83^{\circ} 04.69^{\prime} \mathrm{W}$ & & & \\
$\mathrm{C} 14 / \mathrm{CMP} 4$ & $28^{\circ} 18.33^{\prime} \mathrm{N}$ & 12 Feb 2004 & 24 Mar 2013 & $3328(1110)$ \\
& $83^{\circ} 18.00^{\prime} \mathrm{W}$ & & & \\
$\mathrm{C} 17$ & $25^{\circ} 14.71^{\prime} \mathrm{N}$ & 6 May 2004 & 9 Aug 2008 & $1556(931)$ \\
& $82^{\circ} 12.89^{\prime} \mathrm{W}$ & & & \\
\hline
\end{tabular}
parentheses.

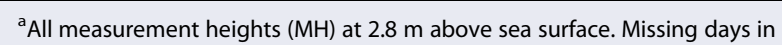
lowing the method of Large and Pond [1981]. For comparison purposes, NCEP winds which are model simulations at the standard $10 \mathrm{~m}$ height [Mesinger et al., 2006] were derived at the same locations as the observations except for 42003, which is outside the WFS domain. Wind stress $\left(\mathrm{Pa}\right.$ or $\mathrm{N} \mathrm{m}^{-2}$ ) was computed from $10 \mathrm{~m}$ winds using an average air density $\left(1.19 \mathrm{~kg} \mathrm{~m}^{-3}\right)$ based on average conditions for temperature $\left(22.8^{\circ} \mathrm{C}\right)$, pressure $(1017 \mathrm{hPa})$, 


\begin{tabular}{|c|c|c|c|c|c|}
\hline Stations & $\mathrm{MH}(\mathrm{m})$ & Location & Start & End & Days (Missing) \\
\hline $42036^{*}$ & 5 & $\begin{array}{l}28^{\circ} 30.00^{\prime} \mathrm{N} \\
84^{\circ} 31.00^{\prime} \mathrm{W}\end{array}$ & 1 Jan 2004 & 31 Dec 2013 & 3653 (385) \\
\hline $42003^{*}$ & 5 & $\begin{array}{l}26^{\circ} 00.42^{\prime} \mathrm{N} \\
85^{\circ} 38.88^{\prime} \mathrm{W}\end{array}$ & 1 Jan 2004 & 31 Dec 2013 & 3653 (348) \\
\hline CWBF1<> & 8 & $\begin{array}{l}27^{\circ} 58.67^{\prime} \mathrm{N} \\
82^{\circ} 49.92^{\prime} \mathrm{W}\end{array}$ & 1 Feb 2005 & 31 Dec 2013 & 3255 (240) \\
\hline VENF1<> & 11.6 & $\begin{array}{l}27^{\circ} 4.32^{\prime} \mathrm{N} \\
82^{\circ} 27.18^{\prime}\end{array}$ & 1 Jan 2004 & 31 Dec 2013 & $3653(490)$ \\
\hline PLSF1^ & 17.7 & $\begin{array}{l}24^{\circ} 41.58^{\prime} \mathrm{N} \\
82^{\circ} 46.38^{\prime} \mathrm{W}\end{array}$ & 1 Jan 2004 & 10 Jul 2012 & 3113 (1014) \\
\hline SANF1^ & 14.6 & $\begin{array}{l}24^{\circ} 27.36^{\prime} \mathrm{N} \\
81^{\circ} 52.62^{\prime} \mathrm{W}\end{array}$ & 1 Jan 2004 & 30 Jun 2012 & 3104 (409) \\
\hline $\mathrm{SMKF}^{\wedge}$ & 48.5 & $\begin{array}{l}24^{\circ} 37.68^{\prime} \mathrm{N} \\
81^{\circ} 6.72^{\prime} \mathrm{W}\end{array}$ & 1 Jan 2004 & 25 Nov 2013 & 3617 (67) \\
\hline
\end{tabular}

${ }^{\mathrm{a}}$ The NOAA NDBC stations are 42003, 42036 (open water buoys), PLSF1, SANF1, SMKF1 (offshore towers), VENF1 (shore station at offshore pier), and the NOAA NOS station CWBF1, also a shore station at offshore pier. MH is meters above sea level. * Open water buoys, <> Offshore pier, ^ Offshore tower. Missing days in parentheses. Station details can be downloaded from http://www. ndbc.noaa.gov. and relative humidity (78\%) at $\mathrm{C} 10$, and a neutral drag coefficient equal to 1.15 $\times 10^{-3}$. As a sensitivity analysis, we performed tests using a variable drag coefficient as proposed by Wood et al. [2012]. The results were equivalent.

For comparison with NCEP winds provided at $6 \mathrm{~h}$ intervals, all observations were preconditioned by deriving $40 \mathrm{~h}$ lowpass filtered sequences (using a fifthorder Butterworth filter, $6 \mathrm{~dB}$ down at $39 \mathrm{~h}$ and $20 \mathrm{~dB}$ down at $32 \mathrm{~h}$ ) and resampling every $6 h$. This separates the higher frequencies that are related to sea breeze effects from the lower frequencies with periods longer than 2 days that describe regional wind variability from seasonal to synoptic (associated with the passage of frontal systems).

Although the unfiltered NCEP winds are 6 hourly, filtering is still required when comparing NCEP winds with observations because unfiltered NCEP winds exhibit variability up to semidiurnal frequencies (the Nyquist frequency for 6 hourly data), whereas the $40 \mathrm{~h}$ low-pass filtered observations have little to no energy for periods less than 2 days. Generally, there is very good qualitative (visual) agreement between the COMPS observations and NCEP winds. As an example, velocity components and velocity vector time series are compared at the $\mathrm{C} 13$ location (Figure 3) from June 2011 through June 2012, one of the longest uninterrupted records (Figure 2). Close inspection shows that, though the visual correlation is good, NCEP winds mostly underestimate the COMPS observations. This situation is extant for other COMPS and NOAA stations as well and is addressed below.

\section{Analysis}

\subsection{Overview}

The analyses that follow consider the temporal and regional variability of the winds over the WFS by describing how vector sequences covary with one another. Time domain analyses were examined using vector correlations as derived by Kundu, [1976]. This approach produces a set of correlation statistics between pairs of two-dimensional vector time series. These statistical metrics are: correlation amplitude, a regression coefficient (or gain), a time lead or lag and relative orientation between the ensemble of observations. This provides a framework with which to examine relationships between observations and between observations and NCEP winds.

After the time domain analysis, the vector relationships were explored in the frequency domain by using statistics derived from vector cross-spectral analysis (rotary spectral analysis), originally derived by Mooers [1973]. This provides a means to examine how the time domain relationships depend on frequency. Specifically, the time domain correlation and gain are equivalent to the coherence and frequency response function in the frequency domain as the mathematics and the geometric interpretations are the same. For simplicity, correlation and gain are used here for both time domain and frequency domain analyses. Both approaches as used here are described in detail by Mayer et al. [2007]. Also, simple derivations and their geometric interpretations (when compared with Mooers [1973] can be found in Mayer et al. [1982].

It will be shown (as in the earlier studies described above) that using shore stations (VENF1 and CWBF1) to estimate offshore winds is problematic because wind magnitudes at the shore underestimate what is observed over open water. Hence questions arise regarding the validity of wind forcing fields (as in NCEP) in offshore areas without supporting in situ observations. To address this question, NCEP winds were compared directly to observations at all locations except at 42003 which is outside the WFS domain as 


\section{QDAU Journal of Geophysical Research: Oceans}
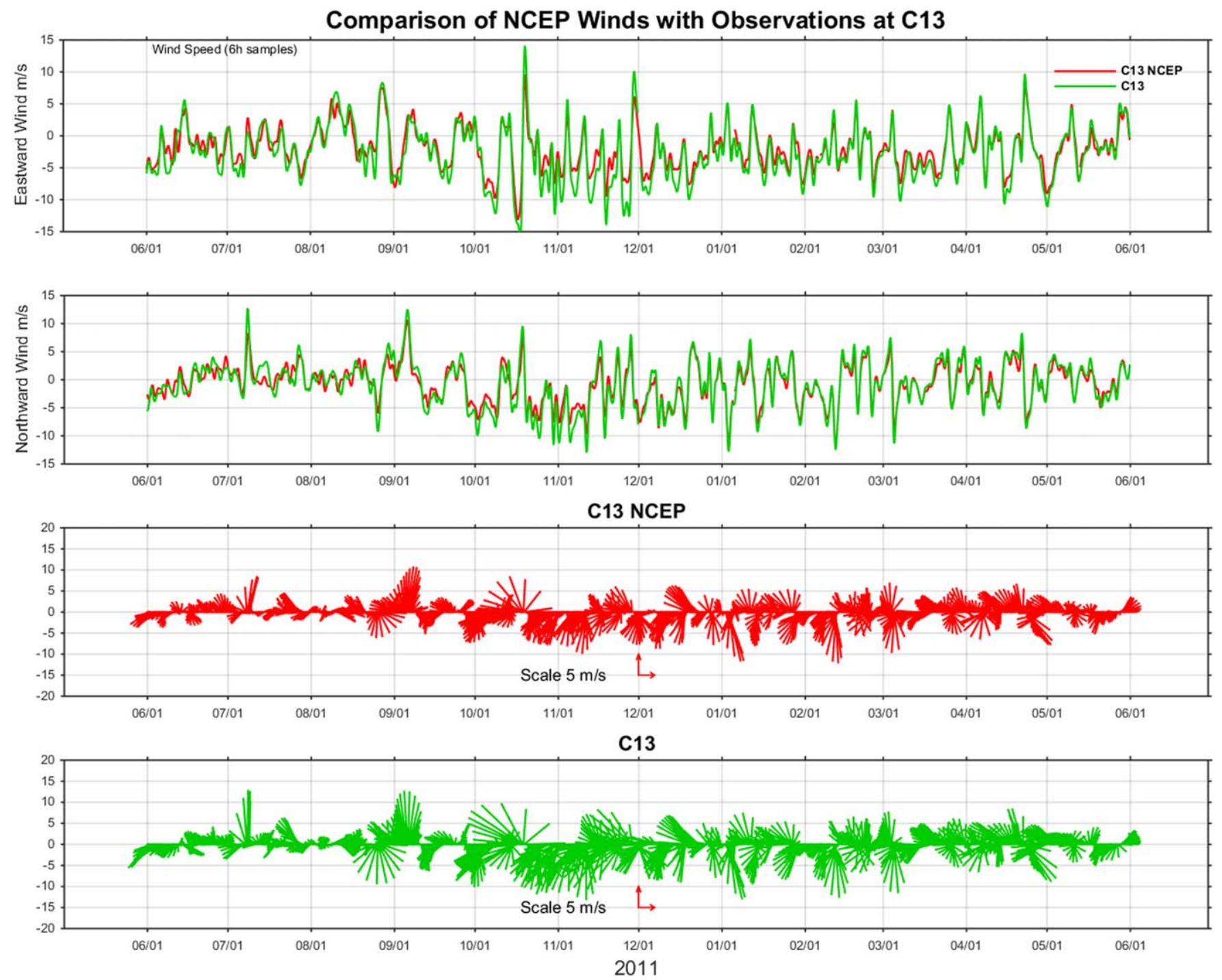

Figure 3. Comparison of $40 \mathrm{~h}$ low-pass filtered COMPS observations and NCEP winds from June 2011 to June 2012 for C13.

noted above. To the extent that NCEP winds underestimate the observed winds, the set of gains for the time domain analysis and the frequency response functions for the frequency domain analysis will be significantly above unity if NCEP winds and observations are used as a set of inputs and outputs, respectively. In anticipation of what the analyses will show, it will emerge that NCEP winds underestimate the observations in most places, with the largest differences being in areas farthest from the nearest NOAA stations.

To provide a context for what follows the winter and summer, seasonal and mean wind stress fields derived from observations in our domain are shown in Figure 4. The mean fields $(\mu \pm €)$ are consistent with those described in Weisberg et al. [2009] and also consistent with the winter and summer fields as given in Liu and Weisberg [2012], where there is a clockwise rotation from winter to summer with much larger amplitudes in winter. The standard errors $(€)$ are shown as crosses, and they are defined as $€=\sigma \mathrm{d} \times \sigma \mathrm{L}$, where $\sigma \mathrm{d}$ is the standard deviation, $\sigma \mathrm{L}$ is the large lag standard error (LLE), $\sigma \mathrm{L}=1 / \sqrt{ } \eta$ where $\eta$ is the number of degrees of freedom (DOF). For the overall means, $\eta>170$, and for the seasonal means, $\eta>40$. These are based on an integral time scale $(\tau)$ —defined in Sciremammano [1979] —of 60-90 h ( $\sim 4$ days) and is the cumulative sum of the autocorrelation squared at large lag. This is approximately where the rate of change of the autocorrelation approaches zero. So with an integral (independence) time scale of $\tau \sim 4$ days, an observation at one 


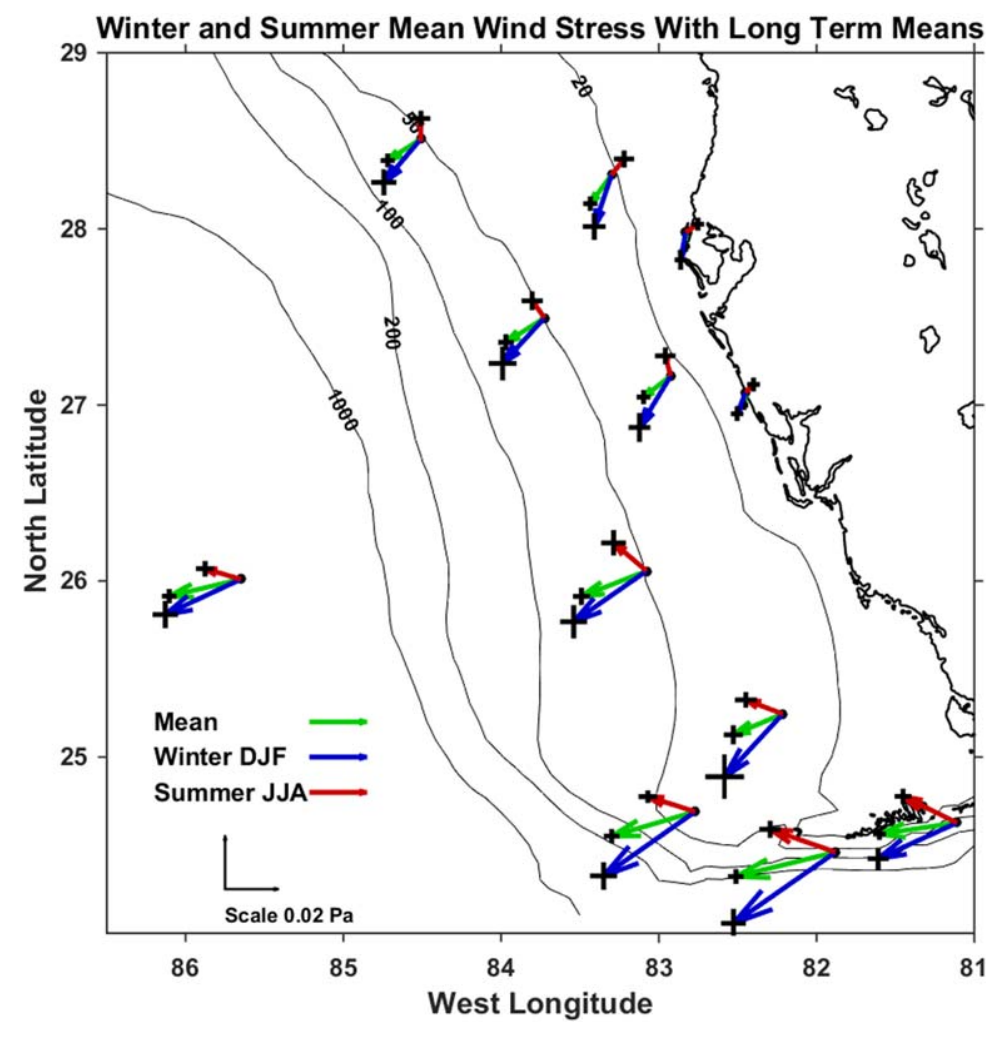

Figure 4. Analysis domain showing the overall mean and winter and summer seasonal wind stress means for the 12 NOAA and COMPS stations. The standard errors $€$ of the mean values $\mu$ are shown as crosses $(\mu \pm €)$ at the vector heads. moment is more or less independent of another approximately 4 days removed. From this the DOF can be computed as $\eta=\mathrm{T} / \tau$ where $\mathrm{T}$ is the record length.

\subsection{Vector Correlation in the Time Domain}

All possible combinations between the 12 NOAA and COMPS stations and associated NCEP winds were analyzed using vector correlation as described above. The principal result is that the statistics depend more or less on the distance between stations and further that observations from the two coastal stations CWBF1 and VENF1 underestimate those observed farther offshore. Additionally, although the NCEP winds are strongly correlated with the observations, they also underestimate the magnitude of the COMPS observations, where these differences generally increase the more removed the COMPS observations are from NOAA stations. For wind speed specifically, the variances of the COMPS and NOAA winds exceed the variances of their concomitant NCEP winds by $0.5-2.0 \mathrm{~m} \mathrm{~s}^{-2}$ with most variance differences being greater than $1.0 \mathrm{~m} \mathrm{~s}^{-2}$.

These wind velocity variance differences are exacerbated when computing wind stress because wind stress is proportional to the product of speed and velocity components. This was quantified by computing the wind stress vector correlations using NCEP winds as inputs and observations as outputs at the same locations. The results provide correlations that are essentially the same and near unity as one would expect, but the gains show how much the NCEP winds underestimate the observations. These calculations, excluding the shore stations (CWBF1 and VENF1) and that at SMKF1, show that all gains are $6 \%-23 \%$ greater than unity (not shown in a table as there are only nine values), providing evidence that the NCEP wind stress field underestimates what is actually taking place. In other words, an NCEP wind stress field would require amplification of $6 \%-23 \%$ to provide better estimates of wind stress in the absence of observations on the WFS.

Vector correlations of wind stress as a function of distance are shown in Figure 5 for a total of 66 possible station combinations. This establishes the correlation metric between all wind stress vector sequences and reflects their temporal and spatial variability on the WFS and is manifested by the correlation slope $(0.068 / 100 \mathrm{~km})$. All correlations exceed the $99 \%$ significance level (SL) for the null hypothesis (2.6 $\sigma \mathrm{L})$ for $\eta>10$ based on an integral or independence time scale of $90 \mathrm{~h}$ as described above. Advancing the null hypothesis requires testing the correlations to determine if they are significantly nonzero which implies a physical relation between the data used. This approach is a normalization of the correlations with respect to $\sigma \mathrm{L}$, where the normalized correlation is a threshold and provides $S L$ on inspection. The smallest value for $\eta$ is between $\mathrm{C} 13$ and $\mathrm{C} 17$ where $\eta=48$, and $2.6 \sigma \mathrm{L}=0.37$. This is much lower than the minimum correlation in Figure $5(0.52)$ and is the worst case, where SL's for the other values in Figure 5 are much less than this (0.37) because as $\eta$ increases, the threshold correlation decreases.

The degree to which either wind stress derived from shore station observations (CWBF1 and VENF1), or wind stress derived from NCEP winds underestimate wind stress derived from open water observations, is 


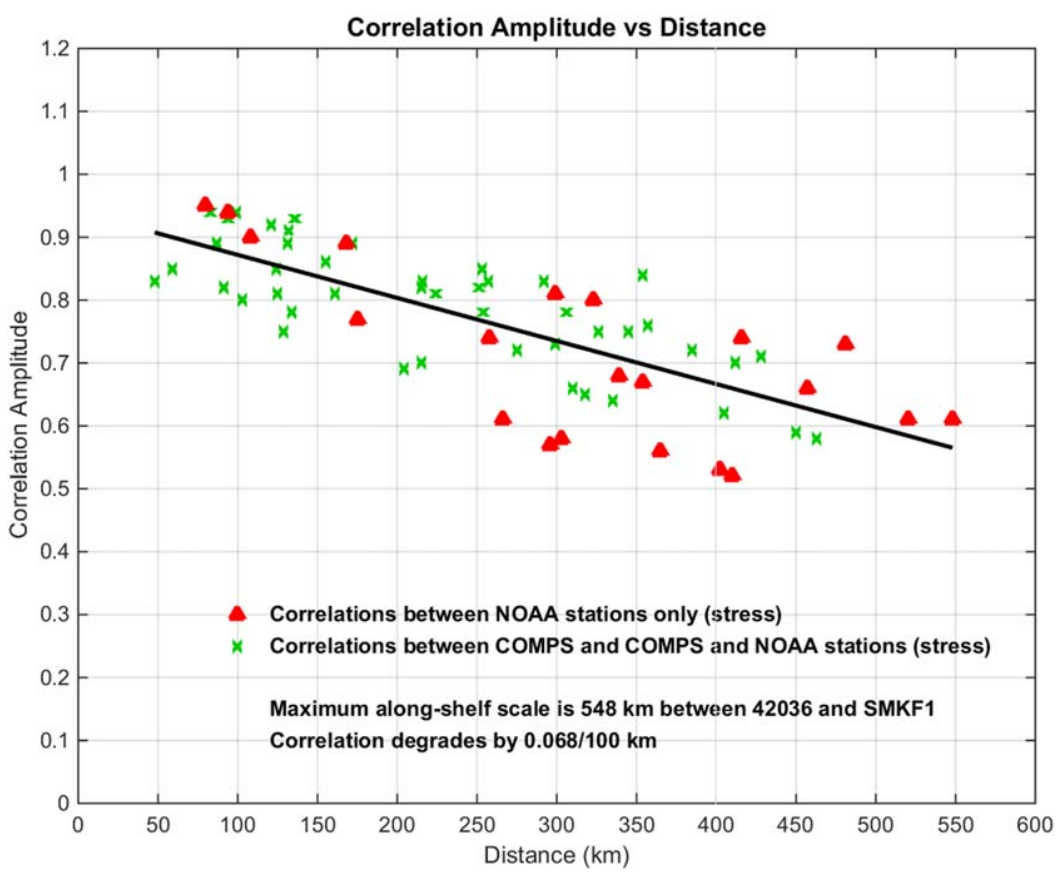

Figure 5. Correlation amplitude as a function of distance between all 12 NOAA and COMPS stations for wind stress. The vector regression shows a correlation degradation of 0.068 per $100 \mathrm{~km}$ by virtue of the temporal and spatial variability of the wind stress field. All values exceed the $99 \% \mathrm{SL}$ for the null hypothesis.

quantified by the set of gains for the time domain analysis. First, to address issues regarding the shore station observations, gains as a function of distance are given in Figure 6 for all combinations. Excluding the shore stations the degradation of the gain is $0.084 / 100 \mathrm{~km}$. The vector correlations were computed in such

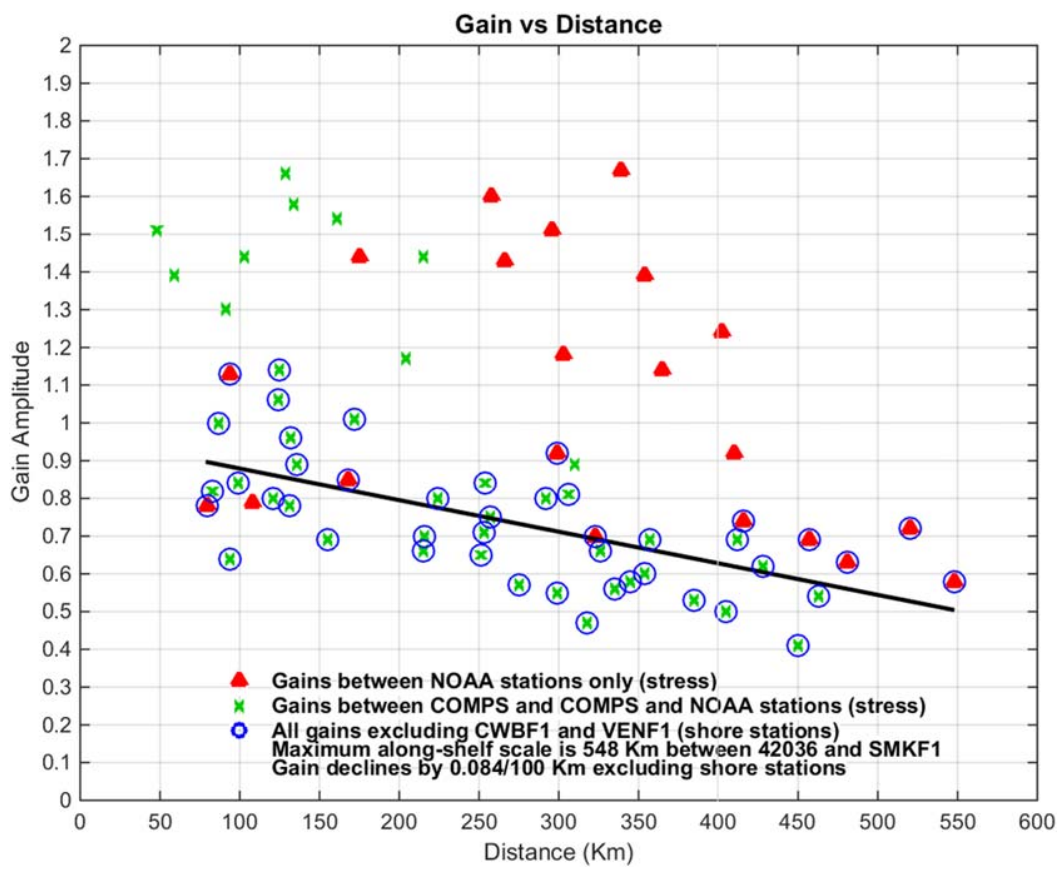

Figure 6. Gain as a function of distance between all 12 NOAA and COMPS stations for wind stress. Excluding the shore stations (CWBF1 and VENF1), the vector regression shows a gain degradation of 0.084 per $100 \mathrm{~km}$ for all of the values that are circled. In contrast, the values (not circled) exceed unity by $14 \%-68 \%$ and are associated with the shore stations as inputs (with two exceptions: CWBF1 with both C17 and SMKF1). 


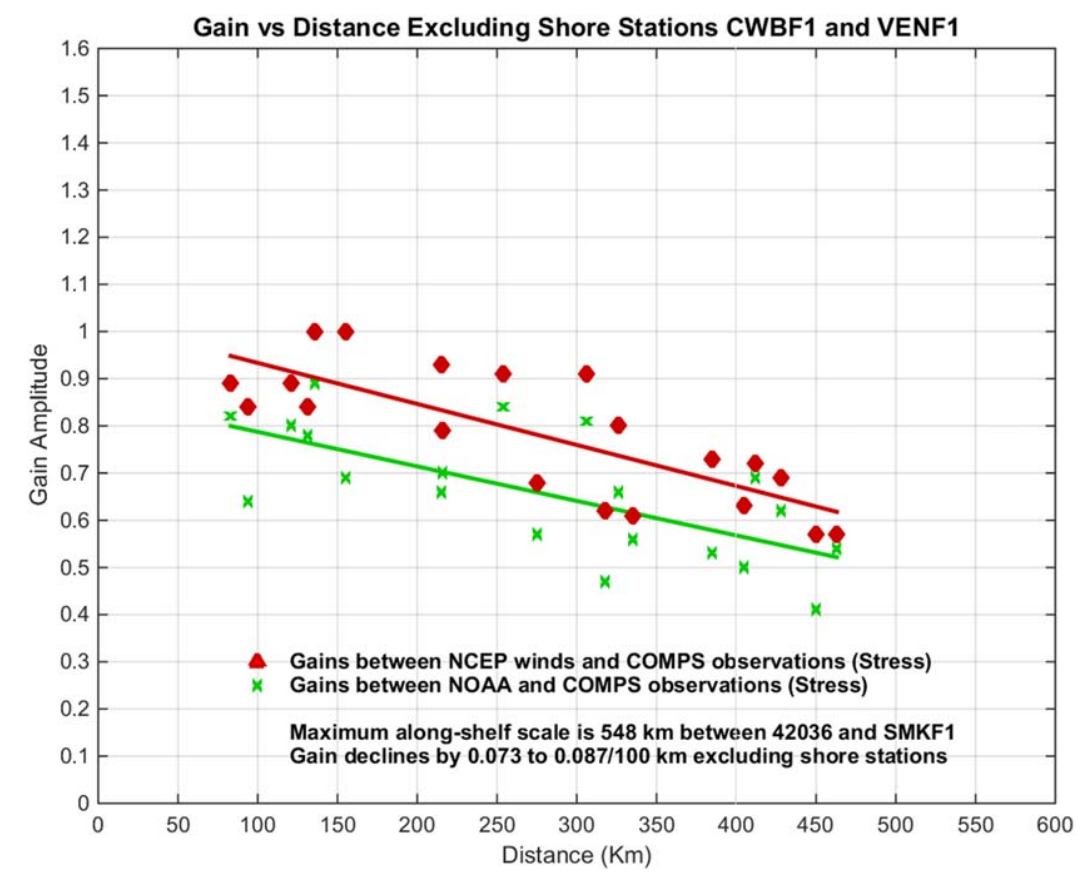

Figure 7. Gains as a function of distance between 10 NOAA and COMPS stations for wind stress. Shore stations are excluded. There are two regression lines. The green line represents inputs derived from NOAA observations and outputs derived from COMPS observations. The red line represents inputs derived from NCEP winds at NOAA locations and outputs derived from COMPS observations. Vector regression shows a gain degradation of 0.073 per $100 \mathrm{~km}$ for inputs derived from NOAA observations and $0.087 / 100 \mathrm{~km}$ for inputs derived from NCEP winds at NOAA locations. The $95 \%$ CL for both slopes are $\pm 10 \%$.

a way that the two shore stations were specified as inputs. In this way if the shore observations significantly underestimate those over open water, the gains will reflect this by having values greater than unity. These gains exceed unity by anywhere from $14 \%$ to $68 \%$. This is significant and makes the point that shore station observations on the WFS are not ideal for estimating wind forcing over open water. There are only two exceptions. These relate to the gain (0.92) between CWBF1 and SMKF1 and the gain (0.89) between CWBF1 and $\mathrm{C} 17$. In the first case, SMKF1 is over $400 \mathrm{~km}$ from CWBF1 in the extreme southeastern part of the analysis domain and in the second case, C17 is over $300 \mathrm{~km}$ from CWBF1 (Figure 1). Distances over $300 \mathrm{~km}$ are enough to degrade both the correlation and the gain. It might also be argued that SMKF1 acts more like a shore station because it is just offshore of Sombrero Key near Marathon in the Florida Keys (Figure 1).

Having addressed the issues related to shore stations, the second consideration regards the fidelity between NCEP winds and observed winds in areas of the domain where NOAA observations are lacking. The analysis in Figure 6 was repeated, but excluding the shore stations CWBF1 and VENF1 and replacing inputs at NOAA locations derived from NOAA observations with inputs derived from NCEP winds (Figure 7). With respect to all statistical quantities described above, whether or not NOAA observations or NCEP winds at NOAA locations are used as inputs, the results are equivalent except for the gains hence only the gains are shown in Figure 7. Note that there are two linear regression lines, for an ensemble of 20 gains, displaced from one another by 0.10-0.15. The green line represents inputs derived from NOAA observations and the red line represents inputs derived from NCEP winds at NOAA locations. Outputs for both were derived from COMPS observations. The gains in Figure 7 with respect to the green regression line are the same as those in Figure 6 excluding the two shore stations (CWBF1 and VENF1). However, the red regression line is what you might expect by using inputs derived from NCEP winds requiring gains that are on average 0.10 to 0.15 greater than those based on NOAA observations. The mean gain difference equals 0.122 plus or minus a standard error of plus or minus 0.017. This is based on the 19 independent samples that result from subtracting the green regression values from the red regression values resulting in upper and lower limits of $0.105(10 \%)$ to $0.139(14 \%)$ greater than unity. The ensemble of differences has a minimum of 0.03 and a maximum of 0.31 . This is likely a consequence of NCEP winds that do not exhibit the same spatial variability as the observed winds. With respect to the individual gains, we computed the $95 \%$ CL for the 20 gain values for each of the two regression sets using 
the F distribution. The $\mathrm{CL}$ are approximately plus or minus $10 \%$. This would apply to the slopes as well. The salient point that emerges is that coastal ocean model circulation fields might be underestimated if the wind stress forcing fields are derived only from NCEP winds and are not complemented by using winds measured in situ as shown by He et al. [2004] and Liu and Weisberg [2012].

\subsection{Vector Correlation in the Frequency Domain}

Of the 12 stations described above, a subset of eight stations was selected for the frequency domain analysis (Figures 8 and 9). The shore stations were excluded for reasons outlined above as well as 42003 (which is outside the WFS domain) and SMKF1 (which is in the extreme southeastern part of the analysis domain). As in section 3.2, using NCEP winds as inputs and observations as outputs at the same locations, vector correlations (coherence) as a function of frequency were derived from an unpolarized cross-spectral analysis as in Mayer et al. [2007]. A 1/10 cosine window was applied to the $40 \mathrm{~h}$ low-pass filtered $6 \mathrm{~h}$ wind stress time series. The resolution frequency is $1 / 400 \mathrm{c}$ (cycles)/d. The range of frequencies spans $1 / 400 \mathrm{c} / \mathrm{d}$ (400 days $\equiv$ $9600 \mathrm{~h}$ ) to $1 / 1.25 \mathrm{c} / \mathrm{d}(1.25$ days $\equiv 30 \mathrm{~h}$ ) though there is little to no energy past $1 / 1.7 \mathrm{c} / \mathrm{d}(1.7$ days $\equiv 40 \mathrm{~h})$ because of $40 \mathrm{~h}$ low-pass filtering. The frequency averaging is over a bandwidth $(\Delta \mathrm{B})$ of $0.0022 \mathrm{c} / \mathrm{h}$. This results in a range of DOF where $\eta$ varies from 27 to 41 depending on the length of record available (as close to a year as possible). The $90 \%$ SL for coherence was calculated from the table of the distribution of the coefficient of coherence [Amos and Koopmans, 1963].

Four of the analyses are in Figure 8 for the stations: 42036, SANF1, C12, and C13. The remaining analyses are in Figure 9 for PLSF1, C10, C14, and C17. The correlations (coherence) and gains (transfer function
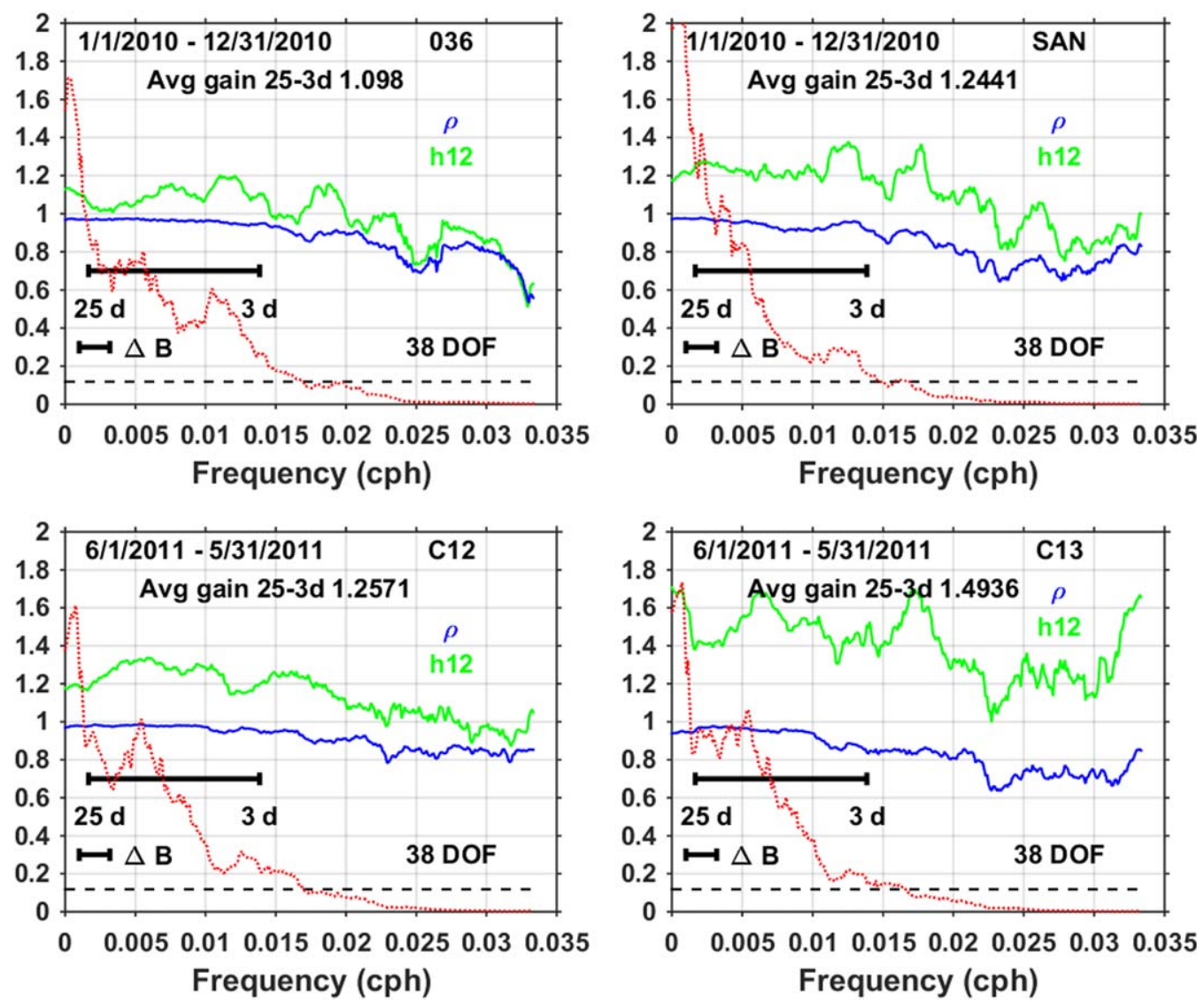

Figure 8. Correlation (coherence, $\rho$, blue) and gain (transfer function amplitude, h12, green) as a function of frequency for the stations: 42036, SANF1, C12, and C13. Time span is indicated for each analysis (approximately 1 year). Inputs are wind stress derived from NCEP winds and outputs are wind stress derived from observations. The $90 \%$ SL for the null hypothesis is indicated by the horizontal dashed line. The dashed red line is the cross-spectral amplitude normalized with respect to the sum of all spectral estimates in percent. The frequency averaging is shown over a bandwidth $(\Delta \mathrm{B})$ of $0.0022 \mathrm{c} / \mathrm{h}$. The low-frequency band (plotted over periods from 25 to 3 days) is also indicated. This includes the synoptic weather band (periods from 10 to 3 days). 

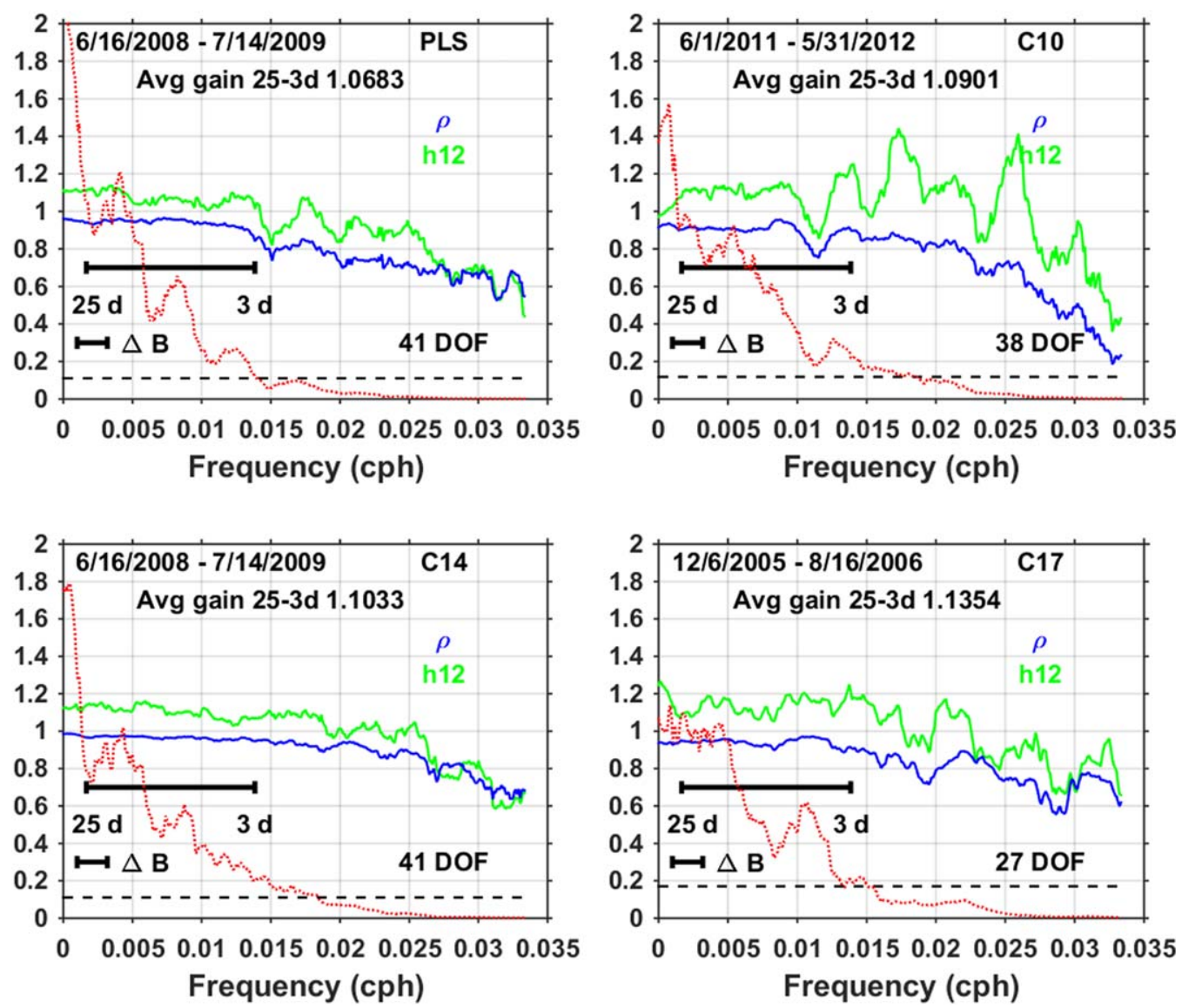

Figure 9. Correlation (coherence, $\rho$, blue) and gain (transfer function amplitude, h12, green) as a function of frequency for the stations: PLSF1, C10, C14, and C17. Time span is indicated for each analysis (approximately 1 year). Inputs are wind stress derived from NCEP winds and outputs are wind stress derived from observations. The $90 \%$ SL for the null hypothesis is indicated by the horizontal dashed line. The dashed red line is the cross-spectral amplitude normalized with respect to the sum of all spectral estimates in percent. The frequency averaging is shown over a bandwidth $(\Delta \mathrm{B})$ of $0.0022 \mathrm{c} / \mathrm{h}$. The low-frequency band (plotted over periods from 25 to 3 days) is also indicated. This includes the synoptic weather band (periods from 10 to 3 days).

amplitudes) across the range of frequencies defined above are plotted for each of the eight stations. Superimposed on these are the normalized cross-spectra, normalized with respect to the sum of all spectral estimates (estimates in percent). Thus, the sum of all normalized estimates would equal 100 . This provides a measure of how relevant the correlations and gains are by virtue of where there are appreciable crossspectral amplitudes, that is correlations and gains have little meaning where there is little or no energy. The time that spans each analysis is approximately 1 year because of the gaps described above (Figure 2). This differs from the time domain analysis where all available data were used. As much as possible synoptic records were chosen. For C10, C12, and C13, the time spans 1 year from June 2011 to May 2012, and for 42036 and SANF1 the time spans the whole year of 2010 (for 1 year $\eta=38$ ). The records from PLSF1 and C14 are slightly longer than a year from June 2008 to July $2009(\eta=41)$ and C17 is the shortest record from December 2005 to August 2006 ( $\eta=27)$.

The seasonal to synoptic weather band provides important wind forcing for the circulation on the WFS [Liu and Weisberg, 2012]. The seasonal to synoptic frequencies span $1 / 90 \mathrm{c} / \mathrm{d} \equiv 0.00046 \mathrm{c} / \mathrm{h}$ (90 days $\equiv 2160 \mathrm{~h}$ ) to the band $1 / 10 \mathrm{c} / \mathrm{d} \equiv 0.0042 \mathrm{c} / \mathrm{h}$ ( 10 days $\equiv 240 \mathrm{~h}$ ) to $1 / 3 \mathrm{c} / \mathrm{d} \equiv 0.0139 \mathrm{c} / \mathrm{h}$ ( 3 days $\equiv 72 \mathrm{~h}$ ), respectively. The quantities in Figure 8 are unambiguous in showing that across these low frequencies the average correlation is near unity and the average gain significantly exceeds unity ranging from $10 \%$ at $42036,24 \%$ at SANF1 to $26 \%$ at $\mathrm{C} 12$ to almost $50 \%$ at C13. The low-frequency band is plotted from $1 / 25 \mathrm{c} / \mathrm{d}$ ( 25 days $\equiv$ $600 \mathrm{~h}$ ) to $1 / 3 \mathrm{c} / \mathrm{d}$ ( 3 days $\equiv 72 \mathrm{~h}$ ) and is somewhat arbitrary to avoid including the very lowest frequencies that are not well resolved due to the record length of approximately a year. With a $\Delta B=0.0022 \mathrm{c} / \mathrm{h}$ a lower frequency cutoff could have been used beginning with a frequency $1 / 40 \mathrm{c} / \mathrm{d} \equiv 0.00104 \mathrm{c} / \mathrm{h}$ (40 days $\equiv$ 
$960 \mathrm{~h}$ ) but the results would have been equivalent even if all the low frequencies had been used because the correlations and the gains do not vary much in the lowest frequencies (Figures 8 and 9). The fact that the gain at $\mathrm{C} 13$ is so large is probably due to location. It is farthest from any of the NOAA stations, and in the absence of more wind observations near this location, NCEP winds are arguably more susceptible to errors. One example of this was given earlier and is indicated in Figure 3 where NCEP winds at C13 underestimate the observations for the time period from June 2011 to June 2012.

The quantities in Figure 9 are similar to those in Figure 8. Across the seasonal to synoptic weather bands, the correlations are near unity and the average gains significantly exceed unity, ranging among $7 \%$ at PLSF1, 9\% at C10, 10\% at C14 to almost $14 \%$ at C17. What is telling is that the gains for the COMPS stations $\mathrm{C} 10, \mathrm{C} 14$, and $\mathrm{C} 17$ are smaller than those in Figure 8 (9\%-14\% greater than unity), whereas those for $\mathrm{C} 12$ and $\mathrm{C} 13$ are $26 \%-49 \%$ greater than unity, respectively. This again is probably due to location. The stations C10, C14, and C17 are much closer to NOAA stations than are C12 and C13. These (C12 and C13) appear to be optimally located along the $50 \mathrm{~m}$ isobath where NOAA observations are lacking and are likely where the most improvement in NCEP winds could be achieved through assimilation of more data.

\section{Summary and Conclusions}

The coastal ocean, the transition region from the shore to the deep sea, is driven by a combination of deepocean and local forcing, which together determines coastal water properties and hence ecosystem functionality. It is in this context that the USF COMPS Program consisting of coastal ocean observing and modeling on the WFS was initiated in 1997.

The objective of the present paper was to investigate the adequacy of presently available WFS wind forcing fields that are used to force WFS coastal ocean circulation models. We compared the NOAA NCEP winds at the standard $10 \mathrm{~m}$ height [Mesinger et al., 2006] with observed winds (referenced to $10 \mathrm{~m}$ height) from all available NOAA stations and COMPS buoys (Figure 1) for a 10 year period from 2004 to 2013 (Figure 2). The following summarizes the salient points arrived at through a combination of vector time series comparisons using time and frequency domain analyses.

Visual comparisons between NOAA and COMPS stations generally show coherent wind field variability, but with stations on and near the coastline having less variance than those offshore. Similarly, NCEP winds tend to underestimate observations (e.g., Figure 3), but unevenly across the domain. These general findings are consistent with previous studies, such as Weisberg and Pietrafesa [1983] for the South Atlantic Bight, Halliwell and Allen [1987] off the west coast of North America, and He et al. [2004] and Liu and Weisberg [2012] for the WFS. With regard to variances on and near the coastline, versus those offshore, it was found that vector correlation gains for wind stress ranged between 1.14 and 1.68 when shore stations were used as inputs and offshore stations were used as outputs. In other words, for wind stress, the shore stations underestimated the offshore stations by 14\%-68\% (Figure 6) except for those noted above between CWBF1 and C17 and SMKF1. Similarly, using NCEP winds as inputs and observations as outputs at the same locations, vector correlations revealed that the NCEP wind stress field underestimates the observations-derived wind stress field (excluding shore stations and SMKF1), requiring gains from 1.06 to 1.23 . In other words, NCEP wind stress requires amplifications of $6 \%-23 \%$ to match wind stress derived from observations and is consistent with the results in Figure 7, where the difference between the two regression lines (the green line using wind stress derived from NOAA winds and the red line using NCEP wind stress at the same NOAA wind locations) is likely caused by NCEP winds that do not include COMPS observations for data assimilation.

In addition to the correlations and gains, the vector time domain analysis also provides relative orientations and lags between the ensemble of observations. The relative orientations were found to be consistent with the vector fields of Figure 4. The lags showed that weather systems tend to progress from west and northwest toward the east and southeast and varied from almost no lag to as much as about $6 \mathrm{~h}$.

The frequency domain analysis results were consistent with those of the time domain analysis. Over seasonal to synoptic time scales, the gains significantly exceed unity and are highest at C12 (1.26) and at C13 (1.49), these two COMPS stations (Figure 8) being farthest from any of the NOAA stations. This contrasts with the gains in Figure 9, which are smaller for C10, C14, and C17 (1.09-1.14), these being closer to NOAA stations than are $\mathrm{C} 12$ and $\mathrm{C} 13$. Furthermore, the results from either time or frequency domain analyses 
show that even at the locations of the NOAA stations (excluding shore stations and SMKF1), NCEP wind stress underestimates the wind stress derived from observations by at least $6 \%$.

We conclude by reiterating two salient points and providing suggestions for improving upon the coastal ocean wind fields used in driving coastal ocean circulation models. First, and as found elsewhere, winds observed at the shore underestimate winds observed offshore. Second, NCEP winds derived from mostly land-based observations also underestimate winds observed offshore. A corollary to these findings is that coastal ocean circulation models that are driven with wind fields that have been underestimated, will underestimate the coastal ocean circulation, as was shown for the WFS by comparing modeled and observed velocity vector time series at specific observing sites [e.g., Zheng and Weisberg, 2012; Weisberg et al., 2014a,2014b,2016b]. Remedies for underestimating the coastal ocean circulation response to wind forcing include adjusting the wind field a priori, as demonstrated by He et al. [2004], or improving the NCEP (or other) coastal ocean wind forcing fields by assimilating more in situ offshore observations. The potential efficacy of additional data for assimilation is suggested by our findings for COMPS stations $\mathrm{C} 12$ and $\mathrm{C} 13$, the two stations farthest away from any of the NOAA stations.

Being that coastal ocean ecosystem functionality begins with water property distributions that are largely determined by the coastal ocean circulation (e.g., see WFS examples in Weisberg and He [2003], Walsh et al. [2003], Weisberg et al. [2015, 2016a], and Liu et al. [2016]), our results are particularly germane to ecosystems-based management of the coastal ocean. Adding more in situ offshore wind observations will likely be a means for improving coastal ocean wind forcing fields and hence coastal ocean model fields of circulation and attendant water properties.

\section{Acknowledgments}

Coastal ocean observing within the College of Marine Science, University of South Florida, was initiated in 1993 through a cooperative agreement with the United States Geological Survey. State of Florida support for a Coastal Ocean Monitoring and Prediction System (COMPS) was obtained in 1997. Various awards were sustaining through the present time with external support now deriving from the Southeast Coastal Ocean Observing Regional Association (SECOORA) as a pass through from NOAA grant NA16NOS0120028. We are particularly grateful for the excellent staff support provided through our Ocean Circulation Group. J. Donovan is responsible for all computer and data organization matters, and J. Law is responsible for all sea going operations. Without such excellent staff support none of our work would have been possible. The in situ wind data can be downloaded from http:// www.ndbc.noaa.gov/. This is CPR contribution 42 .

\section{References}

Amos, D. E., and L. H. Koopmans (1963), Tables of the distribution of the coefficient of coherence for stationary bivariate Gaussian processes, Tech. Rep. SCR-483, Sandia Natl. Lab., Albuquerque, N. M.

Halliwell, G. R., and J. S. Allen (1987), The large-scale coastal wind field along the west coast of North America, J. Geophys. Res., 92, 18611884.

He, R., and R. H. Weisberg (2003), A Loop Current intrusion case study on the West Florida shelf, J. Phys. Oceanogr., 33, $465-477$.

He, R., Y. Liu, and R. H. Weisberg (2004), Coastal ocean wind fields gauged against the performance of an ocean circulation model, Geophys. Res. Lett., 31, L14303, doi:10.1029//2003GL019261.

Hetland, R. D., Y. Hsueh, R. R. Leben, and P. P. Niiler (1999), A loop current-induced jet along the edge of the West Florida Shelf, Geophys. Res. Lett., 26, 2239-2242, doi:10.1029//1999GL900463.

Hsu, S. A. (1986), Correction of land-based wind data for offshore applications: A further evaluation, J. Phys. Oceanogr., 16, 390-394.

Kundu, P. K. (1976), Ekman veering Observed near the ocean bottom, J. Phys. Oceanogr., 6, 238-242.

Large, W. G., and S. Pond (1981), Open ocean momentum flux measurements in moderate to strong winds, J. Phys. Oceanogr., 11, 324336.

$\mathrm{Li}$, Z., and R. H. Weisberg (1999), West Florida continental shelf response to upwelling favorable wind forcing: 2. Dynamics, J. Geophys. Res., $104,23,427-23,442$.

Liu, Y., and R. H. Weisberg (2012), Seasonal variability on the West Florida Shelf, Prog. Oceanogr., 104, 80-98, doi:10.1016/j.pocean.2012.06.001.

Liu, Y., R. H. Weisberg, J. M. Lenes, L. Zheng, K. Hubbard, and J. J Walsh (2016), Offshore forcing on the "pressure point" of the West Florida Shelf: Anomalous upwelling and its influence on harmful algal blooms, J. Geophys. Res. Oceans, 121, 5501-5515, doi:10.1002/ 2016JC011938.

Mayer, D. A., G. C. Han, and D. V. Hansen (1982), Circulation in the Hudson Shelf Valley: Oceanographic studies in New York bight, J. Geophys. Res., 87, 9563-9578.

Mayer, D. A., J. I. Virmani, and R. H. Weisberg (2007), Velocity comparisons from upward and downward acoustic Doppler current profilers on the West Florida Shelf, J. Atmos. Oceanic Technol., 24, 1950-1960.

Mesinger, F., et al. (2006), North American regional reanalysis, Bull. Am. Meteorol. Soc., 87, 343-360.

Mooers, C. N. K. (1973), A technique for the cross spectrum analysis of pairs of comples-valued time series with emphasis on properties of polarized components and rotational invarients, Deep Sea Res. Oceanogr. Abstr., 20, 1129-1141.

Sciremammano, F., Jr. (1979), A suggestion for the presentation of correlations and their significance levels, J. Phys. Oceanogr., 9, $1273-1276$.

Walsh, J. J., et al. (2003), Phytoplankton response to intrusions of slope water on the West Florida Shelf: Models and observations, J. Geophys. Res., 108(C6), 3190, doi:10.1029/2002JC001406.

Weisberg, R. H., and R. He (2003), Local and deep-ocean forcing contributions to anomalous water properties on the West Florida Shelf, J. Geophys. Res., 108(C6), 3184, doi:10.1029/2002JC001407.

Weisberg, R. H., and L. J. Pietrafesa (1983), Kinematics and correlation of the surface wind field in the South Atlantic Bight, J. Geophys. Res., $88,4592-4610$.

Weisberg, R. H., Y. Liu, and D. A. Mayer (2009), West Florida Shelf mean circulation observed with long-term moorings, Geophys. Res. Lett., 36, L19610, doi:10.1029//2009GL040028.

Weisberg, R. H., L. Zheng, Y. Liu, C. Lembke, J. M. Lenes, and J. J. Walsh (2014a), Why no red tide was observed on the West Florida Continental Shelf in 2010, Harmful Algae, 38, 119-126, doi:10.1016/j.hal.2014.04.010.

Weisberg, R. H., L. Zheng, and E. Peebles (2014b), Gag grouper larvae pathways on the West Florida Shelf, Cont. Shelf Res., 88,11-23, doi: 10.1016/j.csr.2014.06.003. 
Weisberg, R. H., L. Zheng, and Y. Liu (2015), Basic tenets for coastal ocean ecosystems monitoring, in Coastal Ocean Observing Systems, edited by Y. Liu, H. Kerkering, and R. H. Weisberg, pp 40-57, Elsevier, London, doi:10.1016/B978-0-12-802022-7.00004-3.

Weisberg, R. H., L. Zheng, and Y. Liu (2016a), West Florida Shelf upwelling: Origins and pathways, J. Geophys. Res. Oceans, 121, 5672-5681, doi:10.1002/2015JC011384.

Weisberg, R. H., L. Zheng, Y. Liu, S. Murawski, C. Hu, and J. Paul (2016b), Did Deepwater Horizon hydrocarbons transit to the West Florida Continental Shelf?, Deep Sea Res., Part II, 129, 259-272, doi:10.1016/j.dsr2.2014.02.002.

Wood, J. E., M. Roughan, and P. M. Tate (2012), Finding a proxy for wind stress over the coastal ocean, Mar. Freshwater Res., 63, 528-544.

Zheng, L., and R. H. Weisberg (2012), Modeling the West Florida coastal ocean by downscaling from the deep ocean, across the continental shelf and into the estuaries, Ocean Modell., 48, 10-29, doi:10.1016/j.ocemod.2012.02.002. 